\title{
Radiofrequency power disinfects and disinfests food, soils and wastewater
}

\author{
by Manuel C. Lagunas-Solar, Nolan X. Zeng, \\ Timothy K. Essert, Tin D. Truong \\ and Cecilia Piña U.
}

Radiofrequency (RF) is an advanced telecommunication technology first invented in the early 1900s, which is in use today for wireless communication worldwide. Because of its ability to penetrate and heat various materials, RF has the potential to disinfect and/or disinfest food, agricultural and environmental materials. However, research to validate this approach has been restricted by limited understanding of how RF photons interact with materials, and by limited access to and the high cost of its source electronics. Since the early 1990s, we have conducted research at UC Davis on continuous RF power applications using nonconventional RF systems and new operational concepts. Laboratory tests have successfully demonstrated the effectiveness of RF power to disinfect and/or disinfest fresh produce, rice, soils, agricultural wastewater, and other foods and materials. Likewise, rapid pulses of $R F$ are lethal to arthropod pests and may provide a nonthermal disinfestation process for fresh, temperaturesensitive commodities, as well as a promising alternative to the fumigant methyl bromide.

\footnotetext{
$A$ major challenge in producing and distributing disease- and insectfree foods is the need to maintain their sensory and nutritional attributes while minimizing the adverse impacts of treatment. This challenge emerged because of consumer attitudes and market expectations concerning the safety, quality and condition of foods;
}

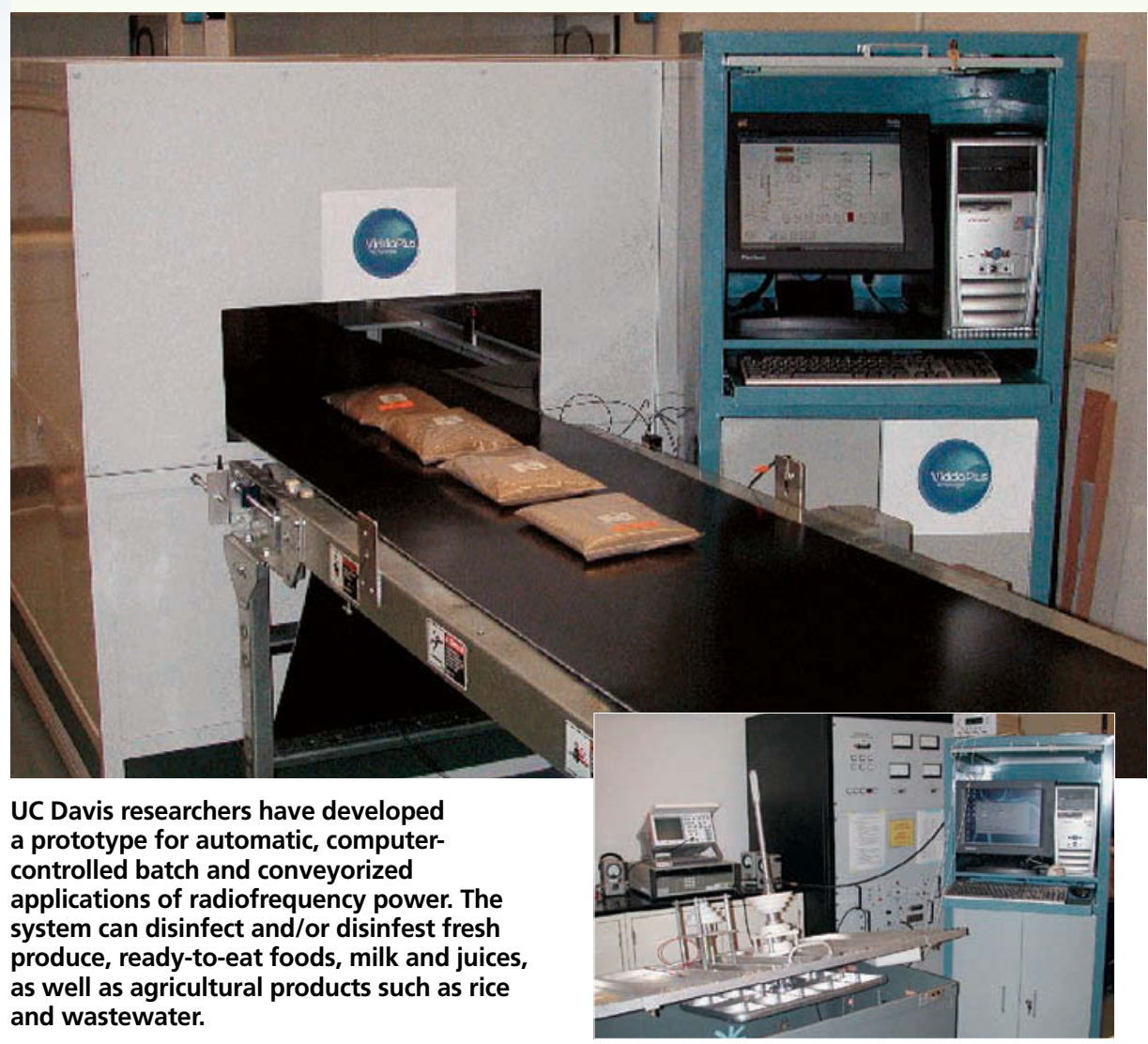

the adverse environmental impacts of agricultural practices; and expanding global markets, which impose logistical demands on regional, national and international trade.

To a large extent, food safety depends on the use of adequate disinfection and disinfestation techniques, while quality is maintained by integrating multiple handling, packaging, and storage and distribution practices. Disinfection is aimed at eliminating spoilage and pathogenic organisms to reduce storage losses and prevent food-related illnesses. The disinfection of nonfood agricultural commodities such as soils, feeds and waste materials is also needed, either because they are recycled or used in food production, or to protect the environment. Disinfestation (control of insect pests) is needed mostly to comply with trade barriers aimed at preventing the spread of nonnative arthropod pests. Pesticides, refrigeration, packaging and modified atmosphere storage are the technologies most often used today for disinfection and disinfestation. New, noninvasive, user-friendly and economically viable processing technologies are needed to meet evolving consumer expectations and trade standards.

A research project was established at UC Davis to study, evaluate and demonstrate new radiofrequency (RF) processing applications for food, agricultural and environmental materials. We review laboratory-scale results for several RF processes with potential commercial applications, and provide preliminary economic estimates for their installation and operation. Our experimental methods are described briefly and generally; the scientific and technical details of many of these results have been or are being reported elsewhere.

\section{How radiofrequency power works}

$\mathrm{RF}$ is an advanced telecommunication technology first invented in the 


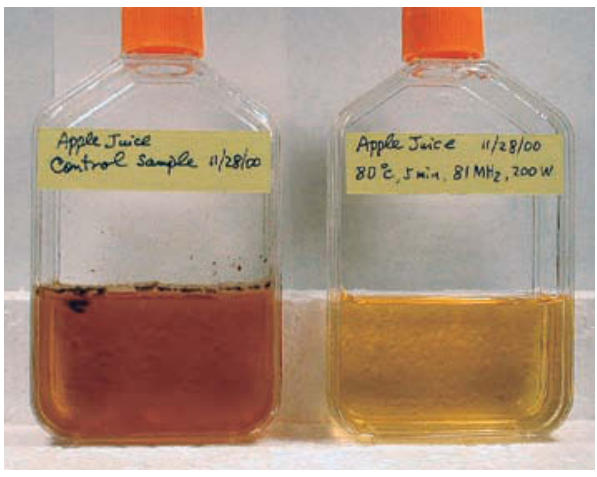

Unprocessed (left) and processed (right) apple juice; the photo shows no microbial growth on the RF-processed sample, even after both samples were stored for 19 months at room temperature.

early 1900s, which is in use today for wireless communication worldwide. Traditionally, RF energy refers to nonionizing electromagnetic radiation with frequencies ranging from approximately 30 megahertz $(\mathrm{MHz})$ (wavelength $=11$ yards [10 meters $]$ ) to $300 \mathrm{MHz}$ (wavelength = 1.1 yards [1 meter]). However, the U.S. Federal Communications Commission (FCC) allows other frequencies to be utilized for industrial, scientific and medical applications (e.g., 13.56 and $27.12 \mathrm{MHz}$ ) (Kasevich 1998). Our studies focused on the use of lower frequencies outside the FCC domain, ranging from 300 kilohertz $(\mathrm{kHz})$ (wavelength $=1,094$ yards [1,000 meters]) to $10 \mathrm{MHz}$ (wavelength $=36.1$ yards [33 meters]). Early tests demonstrated the potential advantages of lower frequencies, in terms of the type and efficiency of RF interactions with different materials. Within the lower frequency range, very high (> 80\%) overall energy-use efficiencies are achievable with modern design and engineering systems. These novel RF systems can be manufactured and operated with significant savings, and increased ruggedness and reliability as compared with conventional RF systems.

RF power is produced when electricity is applied to an RF generator whose signal is amplified and delivered to a parallel electrode system (RF cavity), in which a selected material is placed (fig. 1). Within the RF cavity, an oscillating electric field is created, and energy is transferred to the treated material through electronic-field interactions with dipole or induced dipole molecules

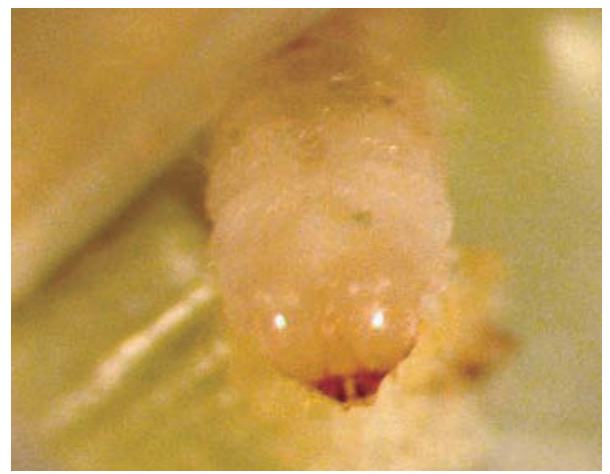

An Angoumois grain moth larva emerges from a rice kernel. In laboratory experiments, RF processing achieved $100 \%$ disinfestation of the moth with no effects on rice quality.

(those formed by the polarization of neutral molecules). These dipole molecules are forced to reorient within the changing electronic field, which results in movement or drifting that causes internal friction and creates thermal energy (heat). The process is known as "RF thermal processing" or simply "RF heating."

At certain frequencies or frequency bands, some foods and nonfood materials can be heated preferentially and faster, creating rapid thermal effects on pests but minimal interactions with the host material. This is due to the difference in electrical conductivity between arthropod pests (high) and the host commodity (low). This process is called "selective or differential RF heating" and could provide an alternative disinfestation process for thermally sensitive fruit and vegetable products. In general, complex organisms such as arthropod pests are more severely and easily affected by heat. The higher response of pests and lesser sensitivity of host commodities offer a window of opportunity for disinfestation with minimal or no impact on the commodity (fig. 2).

The differential effect is generally less effective with microbial contaminants, since microbes are significantly smaller in mass and are usually well attached to a much larger volume (and mass) host, thus being rapidly and effectively cooled. For disinfection to occur, the microbe must reach lethal temperatures, which are usually also deleterious to the host commodity. However, RF heating induces the thermal inactivation of biological organisms (such as fungi, bacteria, protozoa, parasites and nematodes),

\section{RF thermal power formula}

The thermal power induced by RF is given by the following formula:

$$
P=55.61 \times 10-14 \text { E2 } \vee \varepsilon^{\prime \prime}
$$

where $P$ is the thermal power generated $\left(\mathrm{W} / \mathrm{cm}^{3}\right) ; \mathrm{E}$ is the electric field strength in $(\mathrm{V} / \mathrm{cm}) ; v$ is the $\mathrm{RF}$ frequency in $(\mathrm{Hz})$; and $\varepsilon^{\prime \prime}$ is the dielectric loss factor of the material (intrinsic property). The dielectric loss factor $\left(\varepsilon^{\prime \prime}\right)$ largely depends on the material's chemical composition and is essentially the ease by which molecules can be heated by an RF field.

viruses and enzymes, as well as arthropod pests present in heat-tolerant commodities (such as dried fruits, grains, nuts, seeds, wastewater and soils).

Unlike traditional surface heating, RF penetrates deeply into foods and agricultural materials (see formula 1). The surfaces of the treated materials are slightly colder because of radiation losses, and the insides are heated homo-

\section{Definitions}

Dielectrics: material (isolator) that does not conduct electricity

Dipole: material having two equal but opposite charges or magnetic poles

Gram-negative: not forming a color precipitate when treated with alcohol (Gram's staining method for bacteria identification)

Gram-positive: forming color when treated with Gram's method

$\quad$ Abbreviations
cfu: colony-forming units
Hz: hertz
kV: kilovolts
kW: kilowatts
kWh: kilowatt hour
MAP: Mycobacterium avium subsp.
paratuberculosis
MHz: megahertz
RF: radiofrequency
W: watts


geneously and at controllable rates. In general, RF heating eliminates surface overheating, reducing thermal loads and allowing a food's quality and nutritional attributes to be maintained.

\section{Types of RF treatments}

Capacitive heating. Common materials such as water (a major component of most foods), and most cellulose-based and plastic materials used in packaging, are generally inactive or transparent to RF. Other materials such as soils, wood, dried foods, grains, and nut products absorb RF readily and can be heated rapidly. RF photons easily penetrate these commodities, allowing them to be processed in large masses while heating the material thoroughly. This process is known as "capacitive heating."

Conductive heating. Conductive heating is utilized for moist materials such as foods (fresh fruit, vegetables, juices), and agricultural (animal feeds, fishmeal) and environmental (soil, wastewater) materials. The electrical conductivity of these materials is high, promoting the interaction of electrical current in the material to generate heat. Conductive heating can be optimized over a low-frequency band (e.g., $150 \mathrm{kHz}$ to $5 \mathrm{MHz}$ ), with high energy absorption and energy-use efficiencies $(>90 \%)$. When complex mixtures of materials having different RF properties are processed, each component can be heated directly at different rates and a threshold temperature reached to assure efficacy (LagunasSolar et al. 2003).

Ultra-short pulses. RF energy can also be delivered in ultra-short pulses (micro to milliseconds) ( $\mu$ s to $\mathrm{ms}$ ), creating very high peak (instant) RF power levels. When energy is delivered in ultra-short time pulses, biological targets such as insects and mites are subjected to instantaneous high thermal levels without compromising the host material. Pulsed RF generates mostly nonthermal effects in the host. During the pulse, intense electrical fields induce molecular polarization, which forms dipoles; realignment of dipoles with the RF field becomes the major mechanism for energy transfer. These polarization effects can disinfect some biological materials, because it causes cellular changes including modifications in membrane potential, permeability and structural properties (electroporation).

In the laboratory, pulsed RF has induced lethal biological effects on arthropod pests without thermal effects on the host (Lagunas-Solar and Essert 2004). However, for pulsed RF systems to operate reliably with high pulserepetition rates (pulses per second), further system design and engineering is needed. The potential for nonthermal disinfestation of fresh produce in conveyorized operations, with high energy-use efficiency, promises a non- chemical alternative to pesticides that merits further investigation.

\section{Fresh fruits and vegetables}

Selective RF heating effects were suggested as a potential insect control for grains several decades ago (Nelson and Charity 1972), but no demonstrations with fresh produce have been reported.

We exposed fresh fruits and vegetables individually and identically in a RF research cavity (840 watts [W] input power, 6 kilovolts per centimeter $[\mathrm{kV} / \mathrm{cm}], 1 \mathrm{MHz}, 4$ minutes) and the results were normalized for comparison purposes. Because RF heating effects are mostly determined by the material's

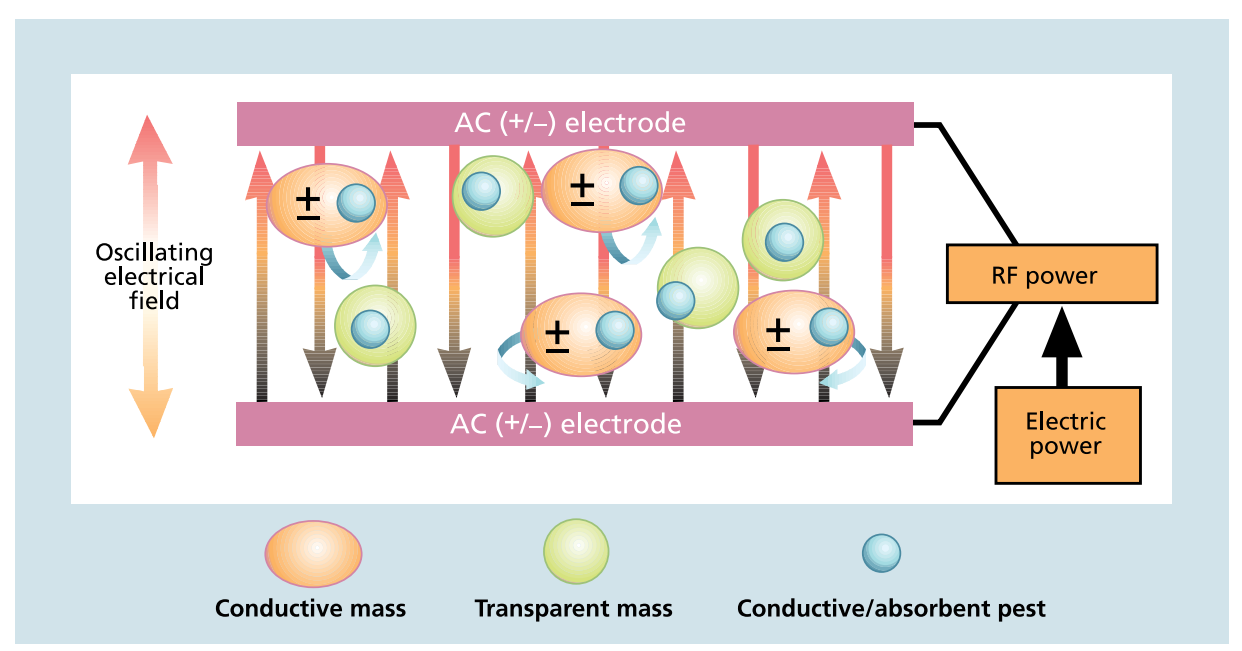

Fig. 1. Components of an RF cavity. Permanent and induced dipoles within the cavity are forced to realign to the changing electronic field, creating friction that generates thermal energy (heat). Molecules that are not permanent dipoles (transparent mass) and cannot be polarized are inactive or transparent within the RF cavity. Insect pests (conductive/absorbent mass) absorb RF, rapidly heating up and dying (disinfestation).

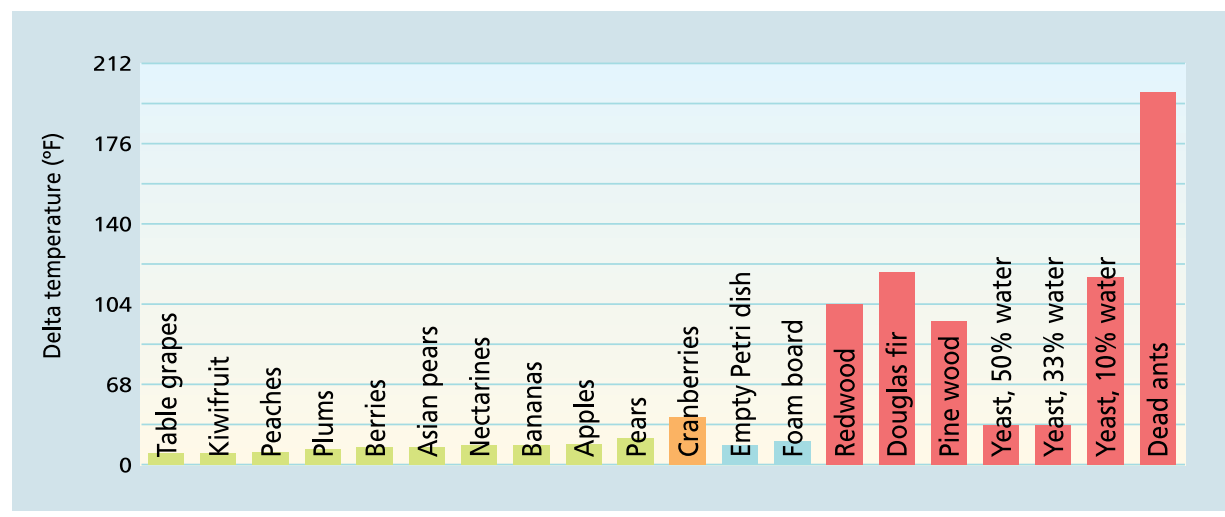

Fig. 2. Differential (selective) heating effects for samples individually treated with $840 \mathbf{~ W}$ at $1 \mathrm{MHz}$ for 4 minutes, with an electric field of $6 \mathrm{kV} / \mathrm{cm}$. Temperatures were measured with nonmetallic (alcohol) thermometers during RF processing; the change in temperature is shown. Similar results were obtained with fresh vegetables (asparagus, carrot, cucumber, eggplant, garlic, onion, pepper, potato) (data not shown). 
chemical composition (see formula, page 193), powdered yeast was used to represent microbes (e.g., fungi, bacteria, protozoa) while ants (Pogonomyrmex subdentatus) were chosen as surrogates for insect and mite pests. We also studied materials commonly used to package fresh produce, such as foam board, wood (Douglas fir, pine and redwood) and polyethylene.

Significantly different heating rates and temperatures were observed between the commodities (lowest heating rates), packaging materials (medium) and particularly model pest contaminants (highest) (fig. 2). Minor heating $\left(\sim 54^{\circ} \mathrm{F}\left[\sim 12^{\circ} \mathrm{C}\right]\right.$ maximum for cranberries) was observed in fresh commodities with a range of $39^{\circ} \mathrm{F}$ to $46^{\circ} \mathrm{F}\left(4^{\circ} \mathrm{C}\right.$ to $8^{\circ} \mathrm{C}$ ) for all others, indicating that a low thermal load (temperature $\times$ time) was well tolerated by fresh commodities. Increased temperatures were rapidly lowered by heat losses reaching ambient temperature $\left(\sim 72^{\circ} \mathrm{F}\left[\sim 22^{\circ} \mathrm{C}\right]\right)$ in a few minutes. Insects reached a level lethal to all arthropod pests $\left(>194^{\circ} \mathrm{F}\right.$ $\left.\left[90^{\circ} \mathrm{C}\right]\right)$. Yeasts heated faster with lower levels of moisture (e.g., dried commodities), suggesting that microbial disinfection in moist products is unlikely. All plastic packaging materials heated at levels similar to the fruits, while wood materials heated faster, suggesting the potential use of RF processing for disinfestation.

Hot water immersion is currently a common practice to disinfest fresh commodities. Selective RF heating for dry thermal disinfestation appears possible and may provide an easily adapted alternative for conveyorized operations with single fruits or fruit packages. If developed, it would be especially useful for organic products. Challenges to developing this process include measuring the RF properties of fresh produce over a frequency band useful to optimize process efficiencies and minimize uneven heating due to the often-irregular shapes of fruits and vegetables. Our operational cost estimates appear to be competitive at $\$ 0.0024$ per pound $(\$ 0.0054$

per kg) and comparable to other RF processes. Prototyping for small-scale field demonstrations will be needed

TABLE 1. RF thermal disinfection of foods and nonfoods inoculated with human pathogens*

\begin{tabular}{|c|c|c|c|c|}
\hline \multirow[b]{2}{*}{ Sample material } & \multirow[b]{2}{*}{ Temperature } & \multicolumn{3}{|c|}{ Reduction levels } \\
\hline & & E. coli 0157:H7 & S. thyphimurium & M. paratuberculosis \\
\hline & ${ }^{\circ} \mathrm{F}\left({ }^{\circ} \mathrm{C}\right)$ & $\ldots \ldots \ldots$ & $\ldots \% \ldots$ & $\ldots \ldots \ldots$ \\
\hline \multicolumn{5}{|c|}{$\begin{array}{l}\text { Ready-to-eat foods/ } \\
\text { Japanese bento box }\end{array}$} \\
\hline Cooked rice & 201.2 (94) & $>99.998$ & > 99.9993 & $\mathrm{n} / \mathrm{a}$ \\
\hline Salmon & $158.0(70)$ & $>99.999$ & $>99.9993$ & $\mathrm{n} / \mathrm{a}$ \\
\hline Shrimp & $179.6(82)$ & > 99.9993 & $>99.9995$ & $\mathrm{n} / \mathrm{a}$ \\
\hline Kamabokot & $161.6(72)$ & $>99.993$ & $>99.9993$ & $\mathrm{n} / \mathrm{a}$ \\
\hline Konnyaku‡ & $165.2(74)$ & $>99.999$ & $>99.998$ & $\mathrm{n} / \mathrm{a}$ \\
\hline Potato salad & $188.6(87)$ & $>99.999$ & $>99.998$ & $\mathrm{n} / \mathrm{a}$ \\
\hline \multirow[t]{3}{*}{ Orange juice } & $129.2(54)$ & $>99.999$ & $>99.994$ & $>9.8$ \\
\hline & $145.4(63)$ & $>99.9996$ & $>99.9993$ & $>99.9995$ \\
\hline & $161.6(72)$ & > 99.9996 & > 99.9995 & > 99.9994 \\
\hline \multirow[t]{4}{*}{ Wastewater } & $113.0(45)$ & $\sim 2$ & $\sim 2$ & Not detectable \\
\hline & $129.2(54)$ & $\sim 9$ & $\sim 99$ & $\sim 2$ \\
\hline & $145.4(63)$ & > 99.9999 & $>99.99999$ & > 99.9999 \\
\hline & $161.6(72)$ & > 99.9999 & $>99.99999$ & > 99.9999 \\
\hline \multirow[t]{5}{*}{ Fishmeal } & $140.0(60)$ & 99.97 & 99.93 & $\mathrm{n} / \mathrm{a}$ \\
\hline & $149.0(65)$ & 99.998 & 99.992 & $\mathrm{n} / \mathrm{a}$ \\
\hline & $158.0(70)$ & $>99.9995$ & $>99.99993$ & $\mathrm{n} / \mathrm{a}$ \\
\hline & $176.0(80)$ & $>99.9995$ & > 99.99993 & $\mathrm{n} / \mathrm{a}$ \\
\hline & $194.0(90)$ & $>99.9995$ & $>99.99993$ & $\mathrm{n} / \mathrm{a}$ \\
\hline \multicolumn{5}{|c|}{ * Reduction levels expressed as percentages were obtained from measured $\log ^{10}$ reduction levels. } \\
\hline
\end{tabular}

to evaluate the efficacy of RF processing and confirm its economics and logistics.

\section{Ready-to-eat foods}

Processed or partially processed foods often contain pathogens from natural or humanmade sources (IFT 2002). For effective disinfection, a threshold temperature must be reached in all of the food's components. With conventional surface heating, the food surface must be overheated, since heat must be conducted throughout its entire volume. We tested RF thermal disinfection in two types of freshly prepared Japanese bento boxes $(\mathrm{n}=30$ each). Samples of each component were inoculated with Escherichia coli O157:H7 and/or Salmonella thyphimurium, both important food pathogens.

Closed plastic packages were treated with the goal of reaching a minimum temperature of $158^{\circ} \mathrm{F}\left(70^{\circ} \mathrm{C}\right)$ in every component. After processing, the treated and control samples were assayed using standard microbiology procedures at the UC Davis Dairy Food Safety Laboratory in the School of Veterinary Medicine. Treated samples in standard Petri dishes were also incubated using selective media for about
21 days and showed no colony formation. Overall, the RF treatments caused no sensory changes, and only minor cosmetic damage occurred to fresh lettuce used in some boxes as a decorative item (table 1).

A panel of Japanese scientists and visitors (Ishida Ltd. Co., Kyoto, Japan) conducted sensory tests and concluded that there were no detectable differences in marketing quality between the RFtreated and untreated boxes. Clearly, RF processing through the package is possible for many foods, reaching disinfection levels without the deterioration of sensory and nutritional properties.

A conveyorized RF process could disinfect ready-to-eat foods quickly, in less than 1 minute. With proper design of the RF cavity, multiple packages could be processed continuously. Based on operational costs (mostly electric power) and without capital cost amortization, the costs would be an estimated $\$ 0.0034$ per pound $(\$ 0.0074$ per $\mathrm{kg}$ ) or approximately $\$ 0.0037$ per box. This RF process would be applicable to similar packaged products for disinfection in a production line, such as grains, dried foods, nut products, cereals, animal feeds and fishmeal. Furthermore, disin- 
fecting or disinfesting food products in the package would help prevent recontamination.

\section{Fresh fruit juices and liquid milk}

Fresh, unprocessed fruit juices are potential sources of human pathogens, particularly those containing several different natural, unprocessed (including organic) ingredients. Contamination can result from field conditions and handling as well as poor hygienic practices during manufacturing. This is why juices, and particularly liquid milk, are heat-pasteurized, but the process can lower nutritional and sensory properties, mostly due to surface overheating. (Nonpasteurized fruit juices are available in some segments of the market.) A homogeneous and less energy-intense thermal process would improve and preserve quality.

Samples (100 milliliters [mL]) of fresh orange juice (Sunkist Growers), apple juice and cider (Martinelli, Apple-a-Day), were innoculated with E. coli O157:H7 and S. typhimurium at about 106 colonyforming-units per milliliter [cfu/mL] and treated with RF (200 W, $13.3 \mathrm{MHz}$, $1 \mathrm{kV} / \mathrm{cm}, 1$ minute). Samples of liquid milk inoculated with Mycobacterium avium subsp. paratuberculosis (MAP), a bacterium believed to be resistant to conventional heat pasteurization, were also RF processed. In addition, nearly a dozen freshly made unpasteurized fruit smoothies were prepared from raw fruits, processed with RF and tested for differences in sensory properties.

Because of their mixed composition (including apple, berries, carrots and oranges), these smoothies and fruit juices heated rapidly and homogeneously in less than 1 minute (table 1). RF process-

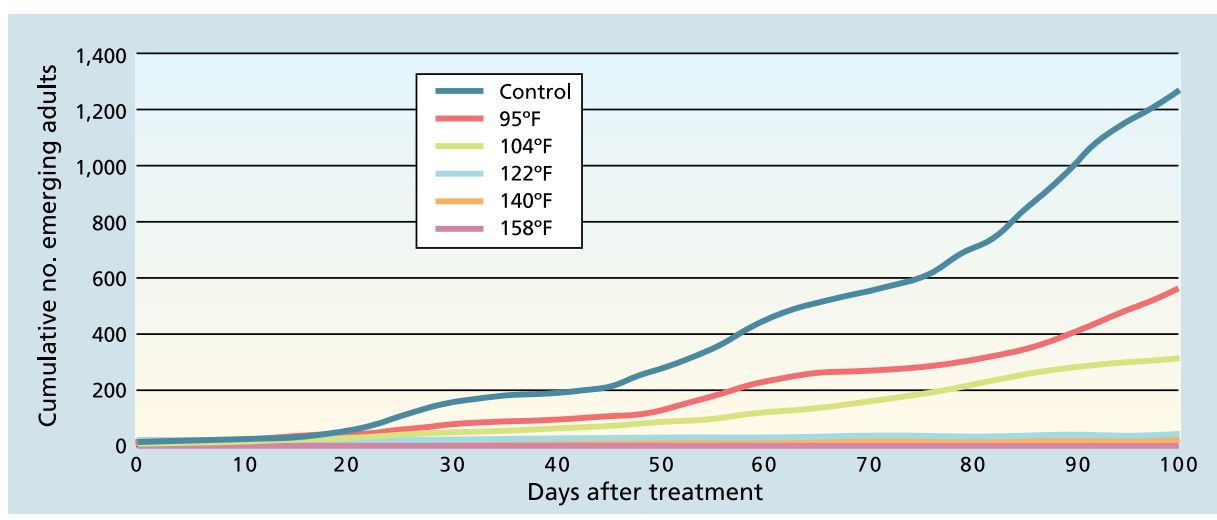

Fig. 3. RF thermal disinfestation effects on naturally infested (Angoumois grain moth) paddy rice. Triplicate samples (155 grams each; 465 grams total) were treated at $95^{\circ} \mathrm{F}$ to $158^{\circ} \mathrm{F}\left(35^{\circ} \mathrm{C}\right.$ to $\left.70^{\circ} \mathrm{C}\right)$ using $100 \mathrm{~W}$ of $385 \mathrm{kHz}$ RF photons, for 5 minutes. Emerging adults were observed for up to 100 days to include overall emergence (survival) from eggs, larva and pupa stages, and compared to controls (not treated). Emergence was controlled at $122^{\circ} \mathrm{F}$ to $158^{\circ} \mathrm{F}\left(50^{\circ} \mathrm{C}\right.$ to $\left.70^{\circ} \mathrm{C}\right)$. ing was reproducible and achieved total destruction of the pathogens, as shown by the absence of colonies after thermal incubation $\left(\sim 7\right.$ days, $\left.98.6^{\circ} \mathrm{F}\left[37^{\circ} \mathrm{C}\right]\right)$. Panels of industry experts determined that RF processing did not affect the sensory properties of either smoothies or fruit juices.

A conveyorized RF system for fresh juices, smoothies and milk could provide processing capabilities in the production line (on-line), and achieve disinfection in-the-package in less than 1 minute, while meeting design and engineering challenges similar to those of ready-to-eat foods. Operational costs, mostly for electric power, were an estimated $\$ 0.0031$ per pound, or $\$ 0.0016$ per gallon ( $\$ 0.0060$ per liter). RF systems for disinfecting fruit juices could be built with a range of processing capacities, allowing its use by small operators or those demanding larger throughput.

\section{Disinfestation of paddy rice}

We tested commercial samples of paddy rice naturally infested with

\begin{tabular}{|c|c|c|c|c|}
\hline Quality attributes & Controls & $\begin{array}{c}\text { Test } 1 \\
\left(122^{\circ} \mathrm{F}\left[50^{\circ} \mathrm{C}\right]\right)\end{array}$ & $\begin{array}{c}\text { Test } 2 \\
\left(140^{\circ} \mathrm{F}\left[60^{\circ} \mathrm{C}\right]\right)\end{array}$ & $\begin{array}{c}\text { Test } 3 \\
\left(158^{\circ} \mathrm{F}\left[70^{\circ} \mathrm{C}\right]\right)\end{array}$ \\
\hline & $\cdots \ldots \ldots$ & $\cdots \cdots \cdots$ & $\cdots \ldots \ldots$ & \\
\hline $\begin{array}{l}\text { Moisture } \\
\text { Whole kernel }\end{array}$ & $\begin{array}{l}13.5 \pm 0.1 \\
793+1.1\end{array}$ & $\begin{array}{l}13.5 \pm 0.1 \\
81.79\end{array}$ & $\begin{array}{l}13.5 \pm 0.1 \\
78.3+0.5\end{array}$ & $\begin{array}{l}13.5 \pm 0.1 \\
779+0.8\end{array}$ \\
\hline Total rice & $68.1 \pm 0.3$ & $68.3 \pm 0.1$ & $68.2 \pm 0.1$ & $68.0 \pm 0.1$ \\
\hline Dockage & $16.9 \pm 4.8$ & $11.7 \pm 1.0$ & $12.4 \pm 1.6$ & $13.2 \pm 1.7$ \\
\hline Brown rice & $81.1 \pm 0.4$ & $81.4 \pm 0.2$ & $81.3 \pm 0.2$ & $81.3 \pm 0.1$ \\
\hline Whiteness & $44.2 \pm 0.2$ & $44.1 \pm 0.2$ & $44.2 \pm 0.2$ & $44.3 \pm 0.3$ \\
\hline
\end{tabular}

Angoumois grain moth (Sitotroga cerealella), whose larvae and pupae live entirely inside the grain. Chemical fumigation with pesticides such as methyl bromide and phosphine is inefficient because the dispensed gases cannot break through naturally occurring air locks, preventing the fumigant from penetrating or diffusing inside the hollowed grain.

A well-insulated paddy-rice sample holder (polyethylene and foam board) was designed and constructed to contain up to 170 grams of paddy rice and maintain a homogeneous temperature $\left( \pm 1.8^{\circ} \mathrm{F} ; \pm 1^{\circ} \mathrm{C}\right)$ during processing. After treatment, all samples (in triplicate) were transferred to plastic containers with secure lids containing small mesh screens, which maintained moisture and oxygen supply and allowed the surviving insects to grow. Samples were incubated at $82.4^{\circ} \mathrm{F}$ to $86^{\circ} \mathrm{F}\left(28^{\circ} \mathrm{C}\right.$ to $\left.30^{\circ} \mathrm{C}\right)$ and $35 \%$ to $43 \%$ relative humidity for up to 100 days (approximately three to four complete insect life cycles). Every 2 to 3 days, the surviving or emerging adult moth populations were determined and compared to the controls. After each observation, all live adults were removed to allow other life cycles (from eggs, larvae, pupae) to emerge and be assayed. In addition, the quality attributes of all treated and control samples were analyzed by the California rice industry using standard analysis methods.

Disinfestation levels reached 100\% control of all Angoumois grain moth life cycles (fig. 3), and the milling and quality of the rice were not affected 


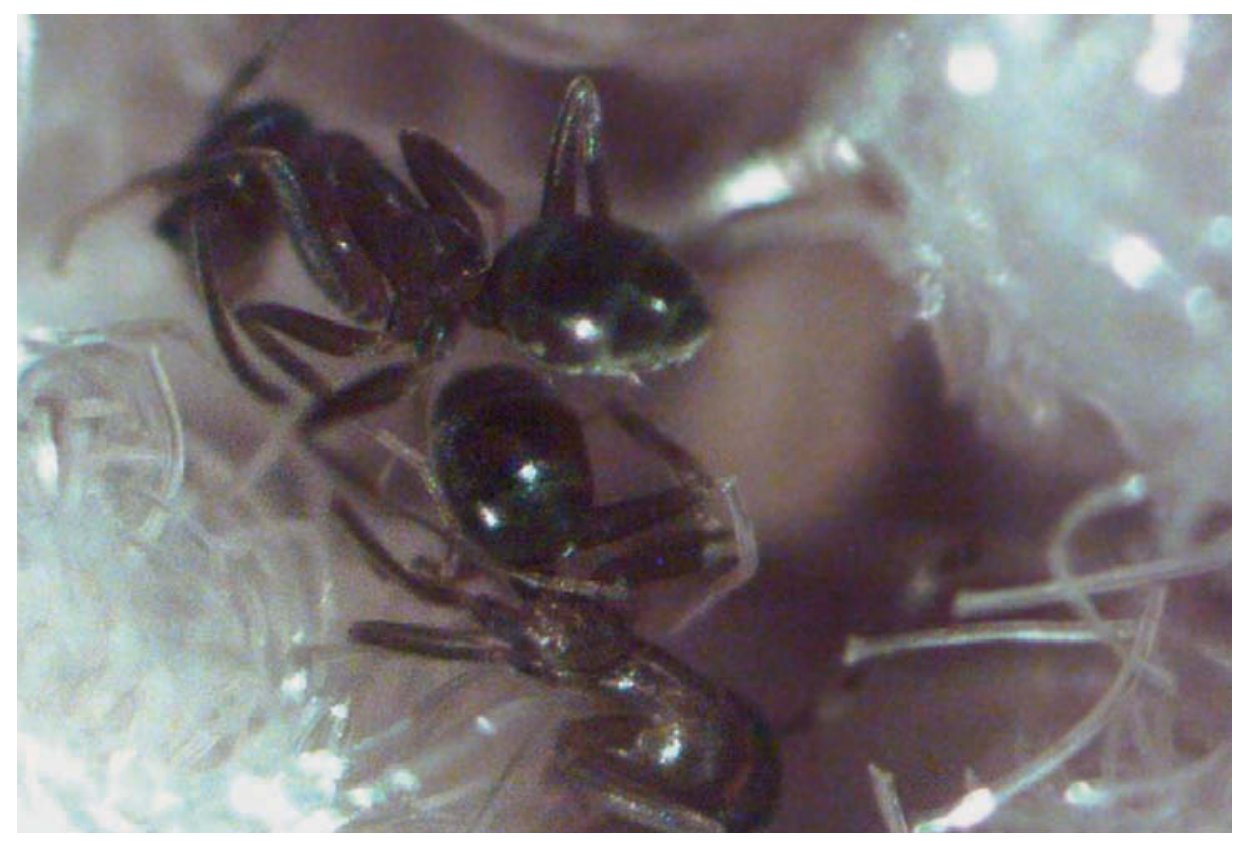

Researchers are investigating the application of RF power to disinfest and disinfect carpets. Specific frequencies were used to rapidly heat insects; ants were killed in a few seconds.

(table 2). RF processing appears to be a promising alternative to fumigation for rice and similar dried commodities such as seeds, nuts and dried fruits. Further research to optimize this process and evaluate sublethal effects on infesting insects is under way with beetles and moths.

An RF conveyorized system could operate commercially with large processing capacity, because rice and other grains are handled at rates of many tons per hour. The logistics of such operations must be further evaluated, but they could offer an effective nonchemical alternative to fumigants at operational costs of $\$ 2.20$ per ton.

\section{Plant seed treatment}

RF processing can disinfect, disinfest and induce favorable biological activation effects (such as increased rate, vigor, and synchronization of germination) in plant seeds without affecting their ability to germinate. We demonstrated RF disinfection with various seeds including tomato, carrot, pepper, cantaloupe, peas and cauliflower. In contrast to hot-water treatments $(\sim$ $131^{\circ} \mathrm{F}$ [ $55^{\circ} \mathrm{C}$ ] for 15 minutes), RF processing allows higher temperatures because heat distribution is better and occurs quickly, in less than 1 minute.

We demonstrated and validated the kinetics of activation in the ger- mination of various types of seed, in collaboration with private industry (Campbell Soup Research Institute, Davis, Calif.). The preliminary data indicates that overall germination is not affected, but its rate (vigor) and timing (synchronization) are greatly improved at thermal loads (temperature and time) capable of simultaneous disinfection and disinfestation. The application of RF to process plant seeds would decrease the risk of recontamination in packaged seed products. Batch or conveyorized operations are also feasible. The operational cost of this treatment is estimated at $\$ 2.20$ per ton. Because seeds are not a high-volume commodity, less-expensive RF systems with relatively low power capacity can be used.

\section{Treating agricultural wastewater}

We investigated the disinfection of agricultural wastes using wastewater from dairy and animal farms in Tulare County. Wastewater samples $(100 \mathrm{~mL})$ were inoculated with $S$. thyphimurium, E. coli O157:H7 and MAP, then treated with temperatures between $113^{\circ} \mathrm{F}$ and $194^{\circ} \mathrm{F}\left(45^{\circ} \mathrm{C}\right.$ to $\left.90^{\circ} \mathrm{C}\right)$. Standard biological procedures (diluting, plating, incubating and counting) with appropriate selective media were used to assay in duplicate all treated and control samples.

Measured disinfection effects (percentage reduction) included corrections for the assay's detection limit (400 cfu/mL), while the extrapolated values were calculated from the initial inoculum levels since no colony growth was detected after 21 days of incubation (table 1). In addition, microorganisms present in the original wastewater samples — including gram-positive (data not shown) and other gram-negative bacteria - were reduced by about $99 \%$. RF processing also effectively controlled MAP bacteria, which appears to resist conventional heat pasteurization at similar thermal levels.

RF processing could be technically and economically competitive with chemical (chlorination, ozonation) and UV processing to disinfect wastewater in concentrated animal feeding operations (Lagunas-Solar et al. 2005). The operational costs for wastewater disinfection at a rate of 1 ton per hour would be about $\$ 6$ per ton. Lacking in chemical residues, treated wastewater could be recycled as animal feed or for soil fertilization without having detrimental
TABLE 3. Economic estimates for RF processing at 2,205 pounds $/ \mathrm{hr}(1,000 \mathrm{~kg} / \mathrm{hr})$ *

\begin{tabular}{lcc}
\hline \hline & \multicolumn{2}{c}{ Economic cost factors } \\
\cline { 2 - 3 } Commodity: objectives & RF power & Cost per pound (kg) \\
\hline & $k W$ & $\$$ \\
Fresh produce: disinfection and disinfestation & 48.1 & $0.0024(0.0054)$ \\
Processed foods: disinfection & 66.7 & $0.0034(0.0074)$ \\
Fruit juices: disinfection & 61.7 & $0.0031(0.0069)$ \\
Liquid milk: disinfection & 60.2 & $0.0030(0.0067)$ \\
Paddy rice: disinfection and disinfestation & 22.2 & $0.0011(0.0025)$ \\
Plant seeds: disinfection and disinfestation & 22.7 & $0.0011(0.0025)$ \\
(activation of germination) & & \\
Wastewater: disinfection & 60.2 & $0.0030(0.0067)$ \\
Fishmeal: disinfection & 32.4 & $0.0016(0.0036)$ \\
\hline * Electricity at \$0.10/kWh; overall energy-use efficiency of 81\%. & &
\end{tabular}


effects on soil chemistry or transferring known plant and human pathogens (Lagunas-Solar et al. 2005).

\section{Fishmeal disinfection}

Fishmeal is used worldwide as a high-protein feed ingredient in aquaculture and animal/poultry production. However, it must be disinfected because contamination with microbial pathogens can occur during storage, transportation and distribution. The market demands Salmonella-free fishmeal to avoid recontamination in the animalhuman food cycle.

We investigated RF disinfection at temperatures ranging from $122^{\circ} \mathrm{F}$ to $194^{\circ} \mathrm{F}\left(50^{\circ} \mathrm{C}\right.$ to $\left.90^{\circ} \mathrm{C}\right)$ with commercial fishmeal samples (Corpesca, Santiago, Chile) inoculated with Salmonella sp. and E. coli O157:H7. Between $158^{\circ} \mathrm{F}$ and $194^{\circ} \mathrm{F}\left(70^{\circ} \mathrm{C}\right.$ to $\left.90^{\circ} \mathrm{C}\right)$, no colonies were detected in plated samples after 21 days of observation (table 1), with greater than $99.999 \%$ reduction in microbial pathogens compared to the controls. Simultaneously, the natural flora present was reduced by more than $99.9 \%$, adding further quality assurances to the treated product.

By industry standards, the fishmeal maintained its quality (e.g., protein and lipid contents, moisture) and in vivo digestibility (Lagunas-Solar et al. 2005a) (fig. 4). In addition, due to improved thermal energy distribution and volume heating properties, RF allows a lower thermal load $\left(\sim 662^{\circ} \mathrm{F}\right.$ per minute $\left[350^{\circ} \mathrm{C}\right.$ per minute]) than conventional [surface] heating $\left(\sim 2,462^{\circ} \mathrm{F}\right.$ to $3,272^{\circ} \mathrm{F}$ per minute $\left[1,350^{\circ} \mathrm{C}\right.$ to $1,800^{\circ} \mathrm{C}$ per minute]). The process has been licensed to private industry, which is evaluating its commercial deployment. Operational costs are estimated at about $\$ 3.20$ per ton (table $3)$, much lower than chemical alternatives (about \$15 to \$20 per ton) or conventional heating (about $\$ 25$ per ton).

\section{Agricultural soils and pests}

If implemented successfully, RF techniques could provide a rapid, residuefree and cost-effective alternative to soil fumigation with methyl bromide, which is being phased out globally due to its contribution to ozone depletion. Research on soil disinfection with RF has focused on containerized and nursery soils (Lagunas-Solar et al. 2005b). Microwaves, hot water and steam applications are also being investigated as alternatives to methyl bromide to disinfest and sterilize soils.

Because soils are good dielectrics and RF can easily penetrate them, RF power offers many advantages; but the use of conventional, continuous RF power systems for soils is currently limited due to high startup (capitalization), logistical barriers and somewhat higher opera-

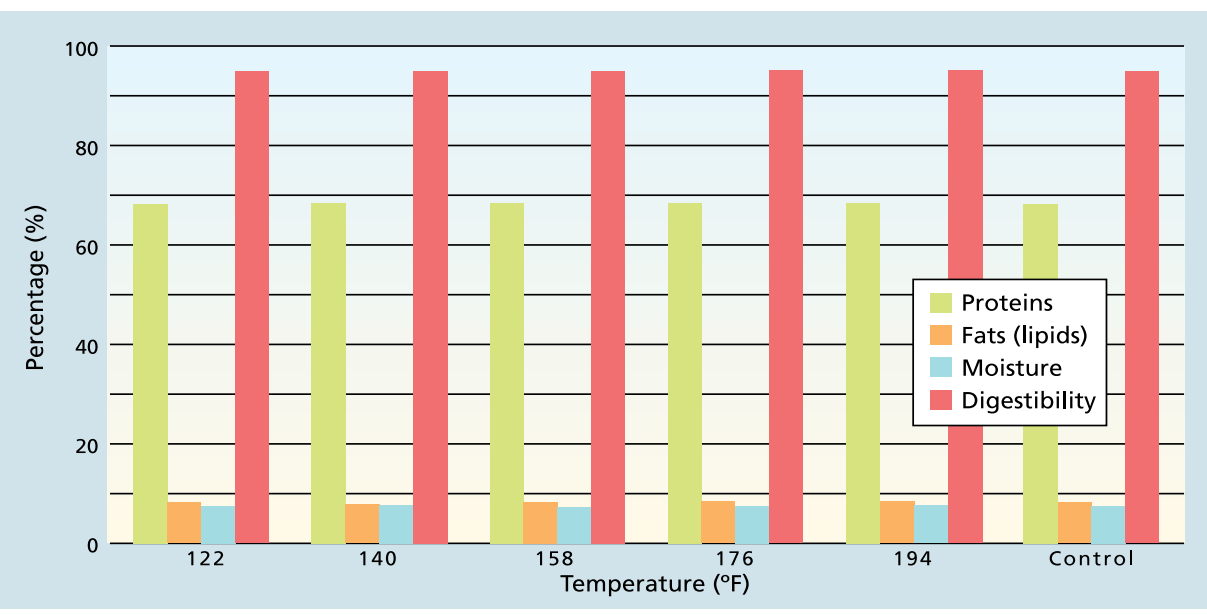

Fig. 4. Percentage of commercially packaged fishmeal samples that retained quality attributes (protein and lipid content, moisture, and protein digestibility) following thermal disinfection at different processing temperatures. Disinfection reached $99.9 \%$ at $140^{\circ} \mathrm{F}\left(60^{\circ} \mathrm{C}\right)$ and $100 \%$ at $158^{\circ} \mathrm{F}$ $\left(70^{\circ} \mathrm{C}\right)$ and above. Animal feeding studies were conducted at the Norwegian Institute of Fisheries and Aquaculture Research, Fyllingsdalen, Norway.

tional costs than methyl bromide. To improve commercial applicability, newly designed and constructed pulsed RF systems are being tested for disinfestation and soil processing (Lagunas-Solar and Essert 2004).

Nematode control. We demonstrated nematode (Panagrellus and Cephalobus sp.) control in agricultural soils in the laboratory using continuous and pulsed RF power applied with high energy-use efficiency (>90\%).

Previously, the lethal temperature for nematodes was experimentally determined as greater than $131^{\circ} \mathrm{F}\left(55^{\circ} \mathrm{C}\right)$, requiring that soils be heated to increase their ambient temperature by $86^{\circ} \mathrm{F}$ to $104^{\circ} \mathrm{F}\left(30^{\circ} \mathrm{C}\right.$ to $\left.40^{\circ} \mathrm{C}\right)$. Control of Fusarium sp. was also demonstrated during the same experimentation.

A newly designed, pulsed RF system was also tested. The system is capable of generating about $200 \mathrm{MW}$ pulses with $\mathrm{kHz}$-level repetition rates using $10 \mathrm{~kW}$ of electric power. Nematode-infested soil samples were treated for 5 to 15 minutes using 400 pulses per second. The soil temperature increased from $73.4^{\circ} \mathrm{F}$ to $113^{\circ} \mathrm{F}\left(23^{\circ} \mathrm{C}\right.$ to $\left.45^{\circ} \mathrm{C}\right)$, indicating that part of the pulsed RF energy was converted to heat. After the treatment, nematodes in treated soil samples were extracted into water overnight and then collected using the Tyler standard screen filter. Nematode mortality was more than $90 \%$ compared with the control. However, 90\% control can also be reached with continuous RF power when heating reaches more than $131^{\circ} \mathrm{F}\left(55^{\circ} \mathrm{C}\right)$. Further studies are under way.

Other research. Pulsed (nonthermal) RF experiments with adult fruit flies (Drosophila melanogaster) and all life cycles of mites (Amblyseius cucumeris, Tyrophagus putrescientae) in fresh table grapes showed $100 \%$ mortality in less than 10 seconds, while inducing negligible temperature changes in the grape $\left(<1.8^{\circ} \mathrm{F} ;<1^{\circ} \mathrm{C}\right)$ (unpublished results). This is due to the high electrical conductivity of arthropods, which allows enhanced, pulsed, RF-induced electric effects at the expense of thermal effects.

Finally, applications of continuous RF power are being developed for the home, particularly to disinfest carpet and garden pests. This application 


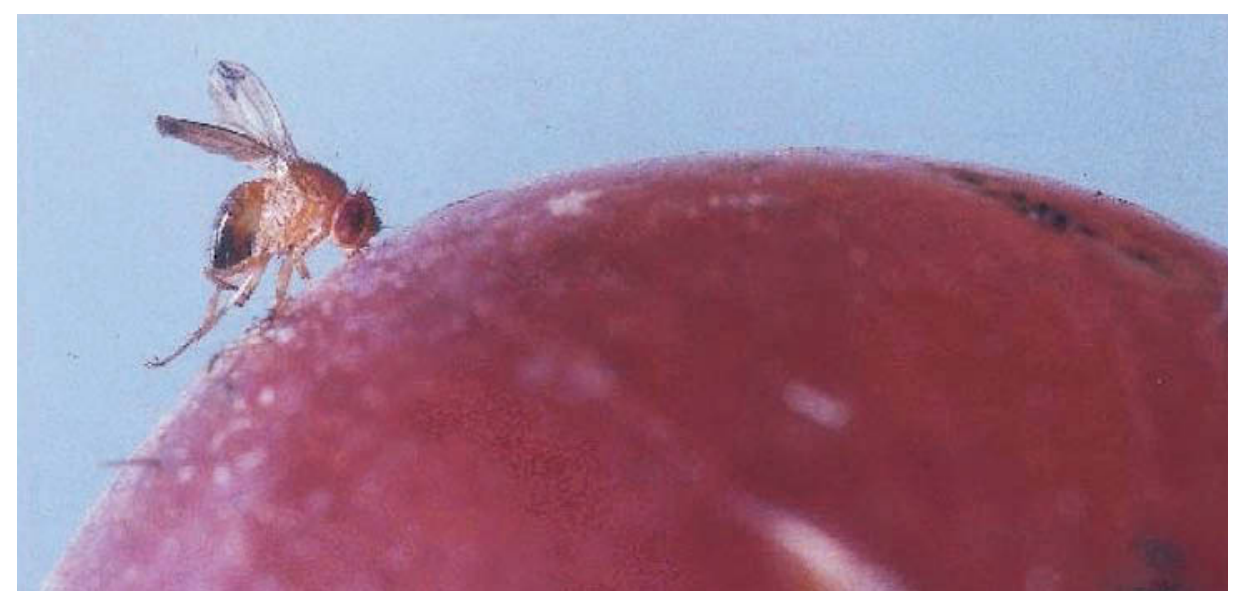

Ultra-short pulses of RF power were used to treat adult flies on the surface of a 'Red Flame' seedless grape berry. No heating effects were detected in the grape, but microscopic observations indicated acute dryness and charring of the fly's integument, wing ruptures and deformed abdomens, all effects related to rapid heating.

utilizes specific frequencies or narrow bands to induce the rapid heating of insects and mites in RF-transparent (nonabsorbing) materials such as carpets or other home materials, thus providing rapid, nonchemical pest control.

\section{Economics of RF processing}

Our preliminary cost estimates for RF processing included the specific heat of materials; the thermal load requirements to achieve effects, the cost of electricity $(\$ 0.10 / \mathrm{kWh})$ and process efficiencies (table 3). They did not include the cost of designing and purchasing RF equipment for specific applications. These estimates are based on the operation of UC Davis laboratory prototype systems, which achieve high energy-use efficiencies (electric-to-RF $>90 \%$ and RF-to-thermal > 90\%).

Although commercial systems currently cost from $\$ 1,500$ to $\$ 2,500$ per $\mathrm{kW}$, we were unable to obtain estimates for newly designed, lower-frequency RF systems. However, we anticipate considerable cost reductions (10 to 20 times) to about $\$ 100$ to $\$ 200$ per $\mathrm{kW}$ for manufacturing systems using solid-state electronics and lower single or narrow non-FCC-approved frequency bands $(<10 \mathrm{MHz})$. These new systems are currently being designed and tested by our laboratory.

Pulsed RF systems offer the potential for even larger energy savings, since intermittent pulses only demand about $10 \%$ of energy consumption. If high energy efficiency and reduced consumption are achieved, RF processing is competitive with conventional heat processing (10\% to 15\% energy-use efficiencies). No regulatory intervention is expected because RF processes are based on either thermal inactivation (continuous RF), or a combination of thermal inactivation with electronicfield effects (pulsed RF). While RF processes would operate outside the allowed FCC frequencies, their operation is fully shielded to prevent RF emissions to personnel and the environment.

Despite experimental demonstrations of its effectiveness and low operational costs, there is no evidence that RF is currently being used commercially to disinfect or disinfest foods or nonfood products in the United States or globally, nor have any such uses been published in the scientific literature. This is believed to be due to the lack of understanding on the mechanisms of interaction between RF photons with foods and nonfood materials, especially in the low-frequency range $(<100 \mathrm{MHz})$, coupled with the challenges associated with designing and operating RF research prototype systems. Nevertheless, a few commercial food (baking and drying) and nonfood (wood drying and disinfestation) applications are known, and medical research is being conducted for thermal tumor ablation treatments. However, these applications have limited impact and have not reached wide acceptance, despite the absence of regulatory barriers.

While RF has tremendous potential, commercial input from the targeted industries is needed to focus and pri- oritize research and development into problems, as defined by industry interests, regulatory demands, and marketing conditions and opportunities.

M.C. Lagunas-Solar is Research Chemist, N.X. Zeng is Research Physicist, T.K. Essert is Principal Electronic Technician, T.D. Truong is Research Assistant, and C. Piña U. is Staff Research Associate, all at Crocker Nuclear Laboratory, UC Davis. (Truong is also Graduate Student, Department of Chemical Engineering and Material Sciences, UC Davis.) The authors thank the following UC Davis professionals for their expert guidance and assistance during collaborative experimentation in their respective fields: James S. Cullor and Wayne L. Smith, School of Veterinary Medicine; James D. MacDonald and Linda Bolkan, Department of Plant Pathology; Edward P. Caswell-Chen and Steven A. Nadler, Department of Nematology; and Zhongli Pan, Department of Biological and Agricultural Engineering. This work summarizes research conducted under the sponsorship of Hortifrut S.A. (Santiago, Chile), the California Dairy Research Foundation and the California Rice Research Board.

\section{References}

[IFT] Institute of Food Technologists. 2002. Emerging Microbiological Food Safety Issues: Implications for Control in the 21st Century; Microbial Ecology and Foodborne Disease. http://members. ift.org/NR/rdonlyres/6ACDE698-6CF1-48EA-9E39B8915D57B56F/0/ecology.pdf.

Kasevich RS. 1998. Understand the potential of radiofrequency energy. Chem Eng Progress:78-81.

Lagunas-Solar MC, Essert TK. 2004. Non-Thermal Disinfestation Method with Pulsed Radiofrequency Power Systems. US Patent Application Serial No. 10/900,990.

Lagunas-Solar MC, Cullor JS, Zeng NX, et al. 2005 Disinfection of dairy and animal farm wastewater with radiofrequency power. J Dairy Sci 88(11):4120-31.

Lagunas-Solar MC, Zeng NX, Essert TK. 2003.

Method for inhibiting pathogenic and spoilage organisms in products. US Patent \#6,638,475. Oct. 28, 2003.

Lagunas-Solar MC, Zeng NX, Essert TK, et al. 2005a. Disinfection of fishmeal with radiofrequency heating for improved quality and energy efficiency. J Sci Food Agr 85:2273-80

Lagunas-Solar MC, Zeng NX, Essert TK, et al. 2005b. Thermal disinfection of soils with radiofrequency power. 2005 Annual Int. Conference on Methyl Bromide Alternatives and Emissions Reductions, p. 38-1 to 38-4. San Diego, CA, Oct 31-Nov 4, 2005.

Nelson SO, Charity LF. 1972. Frequency dependence of energy absorption by insects and grains. Trans ASAE 15(6):1099-102 